\title{
Ecossistemas de Software e Jogos Digitais: Um Modelo de Negócio para os Estúdios Independentes Brasileiros
}

\author{
Bruno Lopes Xavier, Rodrigo Pereira dos Santos
}

\author{
Programa de Pós-Graduação em Informática \\ Universidade Federal do Estado do Rio de Janeiro (UNIRIO) \\ Caixa Postal 458 - 22.290-250 - Rio de Janeiro - RJ - Brasil \\ bruno.xavier@uniriotec.br, rps@uniriotec.br
}

\begin{abstract}
Joining actors and artifacts through a common technological platform has been the strategy used by large software companies, creating software ecosystems (SECO). This approach also encompasses the field of digital games. Focusing on the Brazilian scenario, this work aims to develop a business model for digital games independent studios, using the concepts from SECO research and practice. To do so, it is necessary to explore the Brazilian scenario, mapping its characteristics and later creating a specialized business model. Design Science Research (DSR) is used to support our research.
\end{abstract}

Resumo. Reunir atores e artefatos em uma plataforma tecnológica comum tem sido a estratégia utilizada pelas grandes empresas de software, formando ecossistemas de software (ECOS). Tal abordagem também engloba a área de jogos digitais. Focando no cenário brasileiro, este trabalho objetiva formular um modelo de negócio para os estúdios independentes de jogos digitais, utilizando os conceitos de ECOS. Para tal, é necessário explorar o cenário brasileiro, definindo suas características e, posteriormente, criar um modelo de negócio especializado. Para apoiar o desenvolvimento da pesquisa, é utilizada a abordagem Design Science Research (DSR).

\section{Introdução}

O desenvolvimento de um produto de software único vem sendo substituído por uma estratégia onde múltiplos softwares se integram por meio de uma plataforma tecnológica [Santos 2017]. Tal abordagem está relacionada ao conceito de Ecossistema de Software (ECOS), que é entendido como a interação de um conjunto de atores sobre uma plataforma tecnológica comum, tendo como principal característica a participação de desenvolvedores externos à estrutura organizacional, resultando em várias soluções ou serviços de software [Bosch 2009].

Grandes empresas de software como Amazon, Apple, Google e Microsoft lideram o desenvolvimento de ECOS [Santos et al. 2017]. Com o crescimento destas redes, esta temática vem emergindo como assunto de pesquisa [Lima et al. 2014]. ECOS também está em voga na academia brasileira, sendo abordado nos Grandes Desafios de Pesquisa em Sistemas de Informação como uma área importante para o tema Interoperabilidade em Sistemas de Informação [Boscarioli et al. 2017]. 
O relacionamento entre ECOS e jogos digitais é sustentado por Santos [2017] que afirma que "alguns elementos do processo de desenvolvimento de jogos [...] podem ser destacados e evoluídos para o contexto de ECOS". Berg [2015] adiciona o termo de modelo de negócio para completar o cenário, argumentando que "como a indústria de games $^{1}$ é composta em grande parte por empresas de software, a perspectiva do ECOS se encaixa bem como modelo do ambiente de negócios [...]".

\section{Apresentação do Problema}

Com o advento dos ECOS, o mercado de software alterou seu funcionamento, impactando diretamente no modelo de negócio dos atores da indústria de jogos [Berg 2015]. O crescimento do setor de jogos digitais no Brasil [Sakuda e Fortin 2018] acentua a necessidade de um modelo de negócio focado para os estúdios independentes nascidos neste novo mercado. Uma consequência desta necessidade é apontada pelo fato das empresas de jogos digitais no Brasil possuírem pouco conhecimento sobre a administração de seus negócios [Sakuda e Fortin 2018].

Conforme visto em [Santos 2017], estudos sobre ECOS voltados para o domínio de jogos e entretenimento digital não têm sido desenvolvidos de forma ampla, sendo destacadas algumas necessidades, como: (1) a identificação de papéis e relacionamentos no ECOS; e (2) a integração e extensão de modelos de negócios para apoiar o desenvolvimento de jogos. Estes tópicos acadêmicos são tratados nesta pesquisa.

Para auxiliar na elaboração do projeto de pesquisa, é utilizada a abordagem Design Science Research (DSR), que visa "(1) resolver um problema prático num contexto específico por meio de um artefato e (2) gerar novo conhecimento científico" [Pimentel 2019]. A Figura 1 ilustra os elementos da DSR desta pesquisa, definindo de forma sucinta os tópicos gerais.

\section{Proposta de Solução}

O objetivo é elaborar um modelo de negócio focado nos estúdios independentes ${ }^{2}$ de jogos digitais do Brasil, utilizando os conceitos de ECOS como lente teórica. Para explorar o contexto, esta pesquisa irá se fundamentar em dois estudos: (1) no mapeamento da estrutura e dos relacionamentos de modelos de negócio na indústria de jogos digitais; e (2) na identificação dos problemas, desafios e benefícios emergentes, tanto da indústria como da academia, relacionados à área jogos digitais no Brasil.

O Quadro de Modelo de Negócio (QMN) e o mapeamento dos ECOS serão evoluídos para sistemas web:

1. Sistema de Levantamento dos ECOS de jogos digitais - conjunto de questionários fixos, objetivando a persistência de dados históricos para a indústria e academia. Possibilitará a extração dos dados e emissão de relatórios;

2. Sistema do QMN para estúdios independentes de jogos digitais - disponibilizará um QMN, com foco na persistência das evoluções. Servirá como base para a pesquisa e fornecerá índices para indústria, disponibilizando dados e relatórios.

\footnotetext{
1 "Jogos" em inglês. Não sendo necessariamente vinculado ao conceito de Jogos Digitais.

${ }^{2}$ Pequenos times organizados de forma independente, às vezes, ainda contam com publicadores, mas a criação e produção são independentes e criam jogos com fins de entretenimento [Bittencourt 2017].
} 


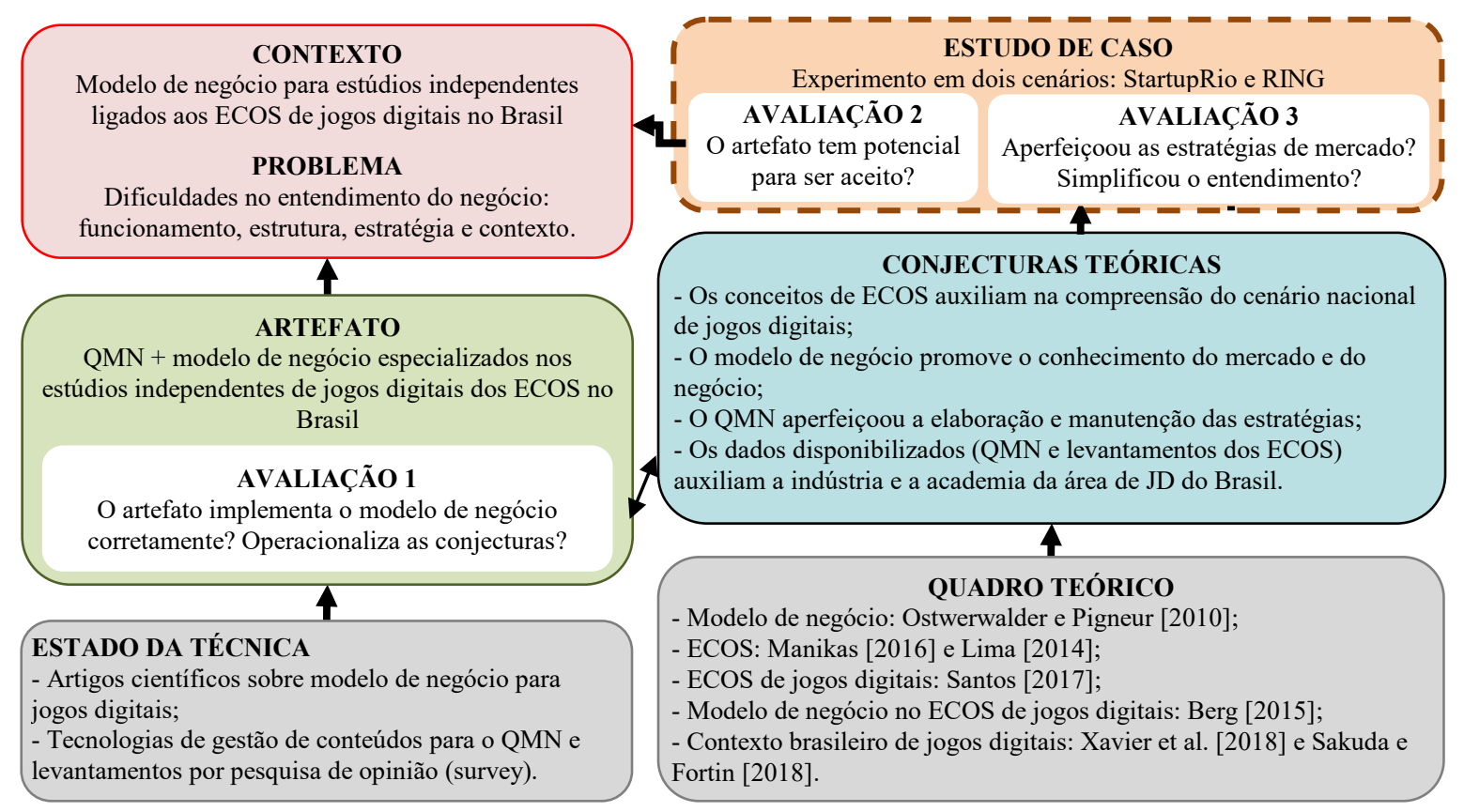

Figura 1. Mapeamentos dos elementos DSR, adaptado de [Pimentel et al. 2019]

\section{Projeto de Avaliação da Solução}

Os possíveis cenários-exemplos para o experimento são: Startup Rio ${ }^{3}$ e RING ${ }^{4}$. Ambos possuem atores que representam estúdios independentes de jogos digitais em formação ou formados recentemente, sendo potenciais entusiastas dos artefatos desta pesquisa.

Haverá dois questionários para validar a solução. O primeiro traçará a curva de valor $^{5}$ atual do processo de modelagem de negócio. Será usada a Escala Likert, com variação de 1 a 5 (de "Muito baixo" até "Muito alto") para avaliar cada conjectura teórica (Figura 1). Os estúdios receberão um coeficiente por hipótese, sendo a média aritmética das questões dividida pelo maior valor de cada resposta. Para a nova curva de valor, será feito um segundo questionário após a aplicação do novo modelo. Ao final, uma comparação entre as curvas de valor definirá o grau de impacto do modelo.

\section{Atividades realizadas}

Em [Xavier et al. 2018], foi feito um estudo exploratório sobre os ECOS de jogos digitais atuantes no Município do Rio de Janeiro. Este estudo será evoluído para abranger os dados do II Censo da Indústria Brasileira de Jogos Digitais [Sakuda e Fortin 2018], bem como dos levantamentos das associações regionais e de órgãos públicos. $O$ objetivo é caracterizar a indústria nacional pela visão de ECOS.

Um estudo em andamento trata da identificação dos problemas, desafios e benefícios da indústria e da academia de jogos digitais por meio de um mapeamento sistemático da literatura. Este trabalho visa emergir tópicos, com uso de Grounded Theory, para caracterizar o cenário nacional, servindo de base argumentativa para o modelo de negócio a ser desenvolvido.

\footnotetext{
${ }^{3}$ Iniciativa público-privada do Estado do Rio de Janeiro e parceiros para fomentar a cultura de empreendedorismo. http://www.startuprio.ri.gov.br/

${ }^{4}$ Grupo de Desenvolvedores de Jogos Digitais do Estado do Rio de Janeiro. https://www.facebook.com/encontroring/

${ }^{5}$ Representação gráfica da variação de um ou vários atributos quantificáveis.
} 


\section{Considerações finais}

Este trabalho apresentou um projeto de pesquisa para a elaboração de um novo modelo de negócio focado nos estúdios independentes de jogos digitais do Brasil apoiado pela visão de ECOS. O objetivo geral é contribuir para a academia e indústria ligadas a área de jogos digitais no Brasil, fornecendo bases de informações relevantes e uma nova perspectiva interligando os conceitos de modelo de negócio, ECOS e jogos digitais.

Como limitações e riscos, é possível citar: (1) o mercado de jogos digitais no Brasil tem alto índice de informalidade [Xavier et al. 2018], dificultando o acesso a informações de fontes confiáveis; (2) os estudos de base e a validação necessitam de interação constante e ampla, sendo uma dependência de alto risco; e (3) a política de dados abertos dos sistemas necessita de apoio jurídico.

Acredita-se que os resultados desta pesquisa serão de grande importância tanto para a academia quanto para a indústria, agregando valor para estes setores complementares e de grande importância para o crescimento nacional.

\section{Referências}

Berg, N. Van den (2015). Business Model Evolution in the Game Software Ecosystem. Master Thesis, Universiteit Utrecht, Utrecht, The Netherlands.

Boscarioli, C., Araujo, R. e Maciel, R. (2017). I GranDSI-BR - Grand Research Challenges in Information Systems in Brazil 2016-2026. 1. ed. Porto Alegre: SBC.

Bosch, J. (2009). From Software Product Lines to Software Ecosystems. In Proceedings of the 13th International Software Product Line Conference, San Francisco, USA, pp. 1-10.

Sakuda, L. O. e Fortin, I. (2018). II Censo da Indústria Brasileira de Jogos Digitais. Ministério da Cultura, Brasil.

Lima, T., Barbosa, G., Santos, R. P. e Werner, C. (2014). Uma Abordagem Sociotécnica para Apoiar Ecossistemas de Software. iSys: Revista Brasileira de Sistemas de Informação 7(3):19-37.

Manikas, K. (2016). Revisiting software ecosystems Research: A longitudinal literature study. Journal of Systems and Software 117(2016):84-103.

Osterwalder, A. e Pigneur, Y. (2010). Business Model Generation. Hoboken: Wiley.

Pimentel, M., Filippo, D. e Santoro F. M. (2019). Design Science Research: fazendo pesquisas científicas rigorosas atreladas ao desenvolvimento de artefatos computacionais projetados para a educação. In Metodologia de Pesquisa Científica em Informática na Educação: Concepção de Pesquisa. 1. ed. Porto Alegre: SBC.

Santos, R. (2017). Ecossistemas de Software no Projeto e Desenvolvimento de Plataformas para Jogos e Entretenimento Digital. In Anais do XVI Simpósio Brasileiro de Jogos e Entretenimento Digital, Curitiba, Brasil, pp. 1327-1337.

Xavier, B. L., Araujo, R. M. e Santos, R. P. (2018). Explorando o Ecossistema de Software de Jogos Digitais. In Anais do XVII Simpósio Brasileiro de Jogos e Entretenimento Digital, Foz do Iguaçu, Brasil, pp. 1526-1533. 